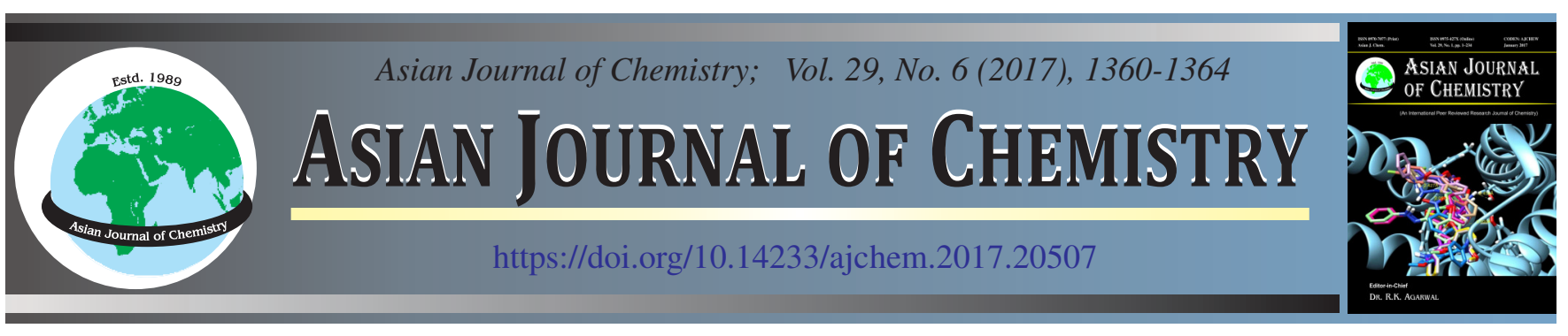

\title{
HPLC Method for Determining Esomeprazole and its Related Substances in Pharmaceutical Formulations
}

\author{
T.S.S. Jagan Mohan ${ }^{1,2, *}$, Datla Peda Varma ${ }^{3}$, KhagGa Bhavyasri ${ }^{4}$, \\ Kancherla Prasad ${ }^{4}$, Khagga MukKanti ${ }^{4}$ and Hitesh A Jogia ${ }^{5}$
}

\begin{abstract}
${ }^{1}$ Research \& Development, Jawaharlal Nehru Technological University, Kakinada-533 003, India
${ }^{2}$ Epione Labs Private Ltd., Nacharam Industrial Area, Hyderabad-500 076, India

${ }^{3}$ Ra Chem Pharma Private Ltd., Techno Industrial Estate, Balanagar, Hyderabad-500 037, India

${ }^{4}$ Institute of Science \& Technology, Jawaharlal Nehru Technological University, Kukatpally, Hyderabad-500 085, India

${ }_{5}^{5}$ Janssen Pharmaceuticals, Jogeshwari (E), Mumbai-400 060, India
\end{abstract}

*Corresponding author: E-mail: victoryjagan1@gmail.com

\begin{abstract}
A green, novel, selective, rapid, precise, accurate and simple isocratic reverse phase stability indicating RP-HPLC method has been developed and validated as per ICH guidelines for estimation of esomeprazole and its impurities in pharmaceutical formulations. Inertsil ODS $(150 \times 4.6 \mathrm{~mm}, 5 \mu)$ stationary phase by using mobile phase $0.05 \%$ glacial acetic acid and isopropanol in the ratio of $85: 15 \mathrm{v} / \mathrm{v}$ at flow rate of $1.0 \mathrm{~mL} / \mathrm{min}$ and column temperature of $50{ }^{\circ} \mathrm{C}$. Esomeprazole was detected at $280 \mathrm{~nm}$. The proposed method was validated as per ICH guidelines for precision, accuracy, specificity, robustness and sensitivity. The proposed method proves its stability by resolving esomeprazole peak from its degradation products in forced degradation study. The proposed method is not only eco-friendly but faster than the official method in EP 8.0 by meeting resolution criteria as per the monograph. The proposed method was capable to determine assay of esomeprazole in the presence of its related substances within the same run. The proposed method can be used for routine analysis in quality control laboratories for its pharmaceutical formulations.
\end{abstract}

Keywords: Esomeprazole, HPLC, Stability indicating method.

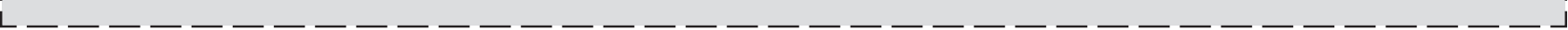

\section{INTRODUCTION}

The objective of green analytical chemistry is to protect the natural environment by developing eco-friendly analytical methods by strictly adhering to the quality practices in pharmaceutical analysis. Reverse phase high performance liquid chromatography is the most extensively utilized technique in the pharmaceutical industry today being employed in nearly every stage of the discovery, development and manufacturing of new drug products [1]. European medicine agency mentioned that solvents like Acetonitrile is ranked as hazardous solvents [2] and because of their inherent toxicity, safe detoxification of the waste solvents is essential, which may lead to high to very high disposal costs [3]. Green liquid chromatography includes reduction in the usage of toxic solvents and changing to eco-friendly solvents [4]. Owing to the toxic properties of acetonitrile, aqueous waste streams containing acetonitrile are typically disposed as chemical waste [5]. Esomeprazole (ES) chemically (magnesium bis[5-methoxy2-[(S)-[(4-methoxy-3,5-dimethylpyridin-2-yl)methyl] sulfinyl]-1 $H$-benzimidazol-1-ide]trihydrate belongs to a class of medicine known as proton pump inhibitors (PPIs) under the brand name of Nexium [6]. Esomeprazole is used in the treatment of gastro esophageal reflux disease (GERD), but is particularly appropriate for those suffering from persistent, recurrent gastro esophageal reflux disease which can cause disruptive, long-term symptoms [7]. In all of the aforementioned chromatographic techniques [8,9], including the EP 8.0 relevant monograph, acetonitrile has been used as a part of mobile phase and sample preparation procedure. The current study describes an eco-friendly, accurate and precise RP-HPLC method for the determination of esomeprazole and its related compounds a, b, c, d, e and f (Fig. 1) in pharmaceutical dosage forms without the need to use of toxic solvents since this drug is being marketed in domestic and international market.

\section{EXPERIMENTAL}

The active pharmaceutical ingredient esomeprazole was procured from the bulk manufacturers Metrochem Pharma Pvt. Ltd. (Hyderabad, India) and its impurities were procured from 
<smiles>CCCCC[S+](=O)Cc1ncc(C)c(C)c1OC</smiles>

(a) ES<smiles>COc1ccc2[nH]c(S)nc2c1</smiles>

(b) Imp-A<smiles>COc1ccc2[nH]c(S(=O)Cc3ncc(C)cc3C)nc2c1</smiles>

(c) Imp-B<smiles></smiles>

(d) Imp-C

(e) Imp-D

(f) Imp-E

Fig. 1. Structures of esomeprazole magnesium trihydrate (ES) and its related compounds

Aurobindo Pharma Ltd (Hyderabad, India). Commercial sample of esomeprazole tablets (Nexpro-40 Tablets), manufactured by Torrent pharmaceuticals Limited, India, were used in the application. HPLC grade isopropanol was purchased from Merck, Germany. Analytical reagents glacial acetic acid, hydrochloric acid and sodium hydroxide, hydrogen peroxide were purchased from Merck, Germany. High purity water was prepared by using the Millipore Milli-Q plus purification system.

Equipments: The Shimadzu HPLC system (Shimadzu, Kyoto, Japan) with a diode array detector was used for method development, forced degradation studies and method validation. The output signal was monitored and processed using Lab solutions software. Thermal stability studies were performed in a dry air oven (Thermolab, India).

\section{Analytical procedures}

Reference method: According to the relevant monograph in the EP [10] the elution was carried out on a ODS column $(125 \mathrm{~mm} \times 4.6 \mathrm{~mm}, 5 \mu \mathrm{m})$. All the analyses were performed at ambient temperature under isocratic conditions with a mobile phase of $1.4 \mathrm{~g} / \mathrm{L}$ disodium hydrogen phosphate buffer solution $\mathrm{pH} 7.6$ : acetonitrile in ratio of $(73: 27$, v/v) at a flow rate of $1.0 \mathrm{~mL} / \mathrm{min}$, using UV detection at $280 \mathrm{~nm}$. Mobile phase was used as a diluent for standard and sample preparation.

Proposed method: The chromatographic separation was achieved on an Inertsil ODS column, $150 \times 4.6 \mathrm{~mm}, 5 \mu$. The mobile phase composition was $0.05 \%$ glacial buffer $(0.5 \mathrm{~mL}$ of glacial acetic acid in $1000 \mathrm{~mL}$ of water) and isopropanol in the ratio of $85: 15(\mathrm{v} / \mathrm{v})$. The mobile phase was filtered through $0.45 \mu$ membrane filter and sonicate to degas it. The flow rate of the mobile phase was kept at $1.0 \mathrm{~mL} / \mathrm{min}$. The column temperature was maintained at $50{ }^{\circ} \mathrm{C}$ and the detector wavelength was monitored at $280 \mathrm{~nm}$. The injection volume was $10 \mu \mathrm{L}$ and the run time was fixed for $20 \mathrm{~min}$. Water and isopropanol in the ratio of 50:50 (v/v) was used as diluent. All the calculations concerning the quantitative analysis were performed with external standardization by measurement of peak areas.

Preparation of standard stock solution: A stock solution of esomeprazole $(0.7 \mathrm{mg} / \mathrm{mL})$ was prepared by dissolving in diluent. Impurity stock solution $(0.1 \mathrm{mg} / \mathrm{mL})$ of the impurities was also prepared in methanol.

Preparation of standard solution: A standard solution of esomeprazole $(0.14 \mu \mathrm{g} / \mathrm{mL})$ was prepared by dissolving in diluent.
Preparation of reference solution: A mixture of esomeprazole $(0.1 \mathrm{mg} / \mathrm{mL})$ and $\mathrm{Imp}-\mathrm{D}(0.1 \mathrm{mg} / \mathrm{mL})$ was prepared by dissolving appropriate amount in diluent.

Preparation of system suitability solution: A mixture of esomeprazole $(0.14 \mathrm{mg} / \mathrm{mL})$ and all impurities $(0.0014 \mathrm{mg} /$ $\mathrm{mL}$ ) was prepared by dissolving appropriate amount in diluent.

Preparation of sample solution: Crush to powder 20 tablets, weigh and transfer the tablet powder equivalent to 3.5 $\mathrm{mg}$ of esomeprazole into $25 \mathrm{~mL}$ volumetric flask add $15 \mathrm{~mL}$ of diluent, sonicate for $30 \mathrm{~min}$ and dilute to volume with diluent. Further filter the solution through $0.45 \mu \mathrm{m}$ pore size nylon 66-membrane filter.

Method development: The main objective of the chromatographic method is to develop a stability indicating method for the separation esomeprazole and its related compounds by using green analytical chemistry principles. Several trails were conducted in the development of a stability-indicating green HPLC method for the analysis of esomeprazole and its related compound in pharmaceutical tablet formulation. Various mobile phase compositions of buffer with green solvents like ethanol and isopropanol were tried, but the combination of buffer and ethanol resulted in a lack of peak symmetry both for esomeprazole and their related compounds. The best results were obtained with $0.05 \%$ glacial buffer $(0.5 \mathrm{~mL}$ of glacial acetic acid in $1000 \mathrm{~mL}$ of water) and Isopropanol in the ratio of $85: 15(\mathrm{v} / \mathrm{v})$ at a flow rate of $1.0 \mathrm{~mL} / \mathrm{min}$ and column temperature of $50{ }^{\circ} \mathrm{C}$ using DAD detector at $280 \mathrm{~nm}$.

Method validation: The proposed method was validated according to the ICH guidelines [11] with respect to parameters like specificity, precision, accuracy, robustness, ruggedness, solution stability, limit of detection (LOD) and limit of quantification (LOQ).

\section{RESULTS AND DISCUSSION}

Optimization of the chromatographic conditions: The prime objective of the chromatographic procedure is to develop an ecofriendly stability indicating method for the separation esomeprazole and its related compounds. Several trails were conducted by considering the green chemistry fundamentals [12], various mobile phase compositions of buffer with green solvents like ethanol and isopropanol were tried, HPLC method in the development of a stability-indicating green HPLC method for the analysis of esomeprazole and its related compound in 
pharmaceutical tablet formulation. Of several solvents and solvent mixtures investigated, the mobile phase $0.05 \%$ glacial buffer $(0.5 \mathrm{~mL}$ of glacial acetic acid in $1000 \mathrm{~mL}$ of water $)$ and isopropanol in the ratio of $85: 15(\mathrm{v} / \mathrm{v})$ at a flow rate of $1.0 \mathrm{~mL} / \mathrm{min}$ and column temperature of $50{ }^{\circ} \mathrm{C}$ using DAD detector at 280 $\mathrm{nm}$ was found to be good and able to resolve esomeprazole and all the impurities (denoted Imp-A to Imp-E) (Fig. 2) by meeting the system suitability requirement in the relevant monograph in the EP 8.0 (Fig. 3). The relative response factor for all the five impurities was determined with respect to esomeprazole (Table-1).
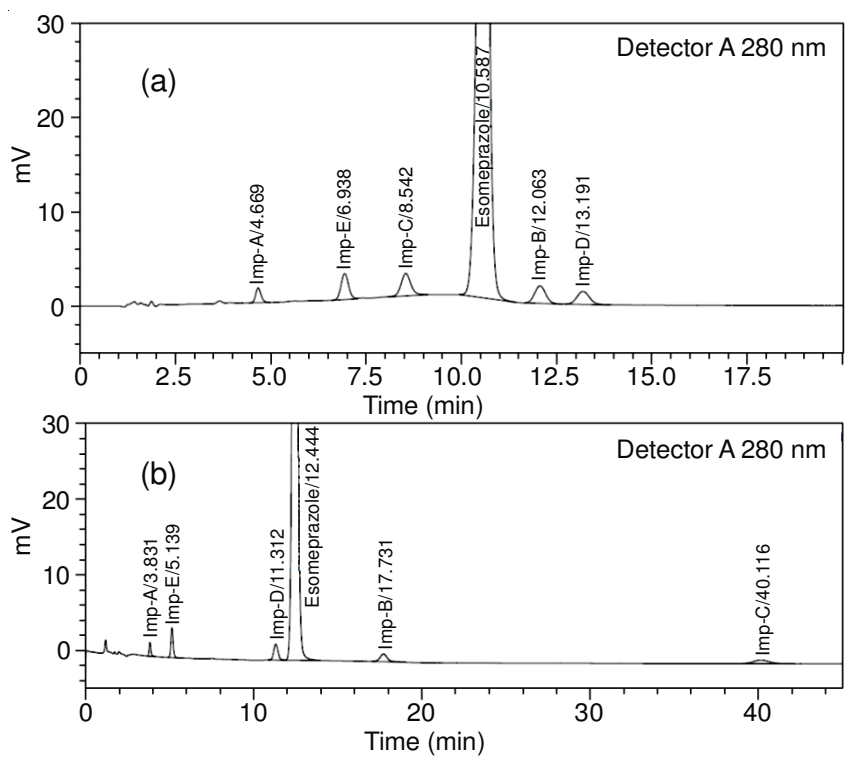

Fig. 2. Separation of system suitability solution using (a) the proposed green method (Run time - $20 \mathrm{~min}$ ) and (b) the EP 8.0 method (Run time $-45 \mathrm{~min})$

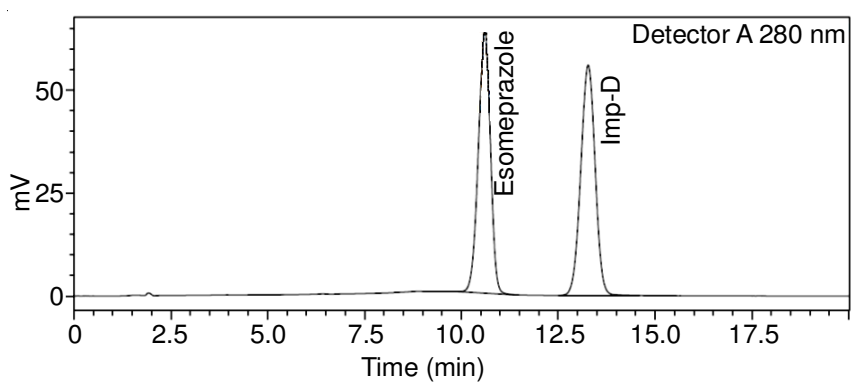

Fig. 3. Resolution solution as per EP monograph using the proposed green method (As per the monograph the minimum resolution should be more than 3.0, observed resolution is 4.2)

\begin{tabular}{cccccc}
\multicolumn{5}{c}{ TABLE-1 } \\
SYSTEM SUITABILITY DATA \\
\hline Name & $\begin{array}{c}\text { RT } \\
(\mathrm{min})\end{array}$ & RRT $^{\mathrm{a}}$ & Resolution $^{\mathrm{b}}$ & $\begin{array}{c}\text { Tailing } \\
\text { factor }\end{array}$ & RRF $^{\mathrm{c}}$ \\
\hline Imp-A & 4.669 & 0.44 & - & 1.2 & 0.61 \\
Imp-E & 6.938 & 0.66 & 7.1 & 1.1 & 1.38 \\
Imp-C & 8.542 & 0.81 & 3.8 & 1.1 & 1.54 \\
ES & 10.587 & 1.00 & 4.2 & 0.9 & 1.00 \\
Imp-B & 12.063 & 1.14 & 2.8 & 1.1 & 1.44 \\
Imp-D & 13.191 & 1.25 & 2.0 & 1.1 & 1.14 \\
\hline
\end{tabular}

${ }^{\text {a }}$ Relative retention times (RRT) were calculated against the retention time (RT) of esomeprazole; ' Resolution was calculated between two adjacent peaks; ${ }^{\mathrm{c}}$ Relative response factor (RRF) was calculated against the response of esomeprazole.

\section{Method validation}

Specificity and forced degradation studies: The specificity of an analytical method represents the ability of the method to measure the analyte in the presence of its degradation products and without having any interference from blank and placebo. Forced degradation studies will help to identify the likely degradation product and the stability indicating power of the method.

Forced degradation studies were performed with esomeprazole tablet dosage form to examine the proposed method regarding its specificity and ability to indicate the stability of esomeprazole. The forced degradation process was performed under acidic $\left(0.1 \mathrm{M} \mathrm{HCl}\right.$ at $\left.25^{\circ} \mathrm{C}, 30 \mathrm{~min}\right)$, basic $(0.1 \mathrm{M} \mathrm{NaOH}$ at $60{ }^{\circ} \mathrm{C}, 25 \mathrm{~min}$ ), oxidative (hydrogen peroxide $(1 \%)$ at 60 ${ }^{\circ} \mathrm{C}, 20 \mathrm{~min}$ ) and thermal conditions (dry conditions at $105^{\circ} \mathrm{C}$, $2 \mathrm{~h}$ ), refluxed with purified water for about $20 \mathrm{~min}$ at $60^{\circ} \mathrm{C}$, exposed to humidity at $25^{\circ} \mathrm{C}$ and $90 \%$ RH for about 15 days. The sample solutions prepared under each set of conditions were filtered through $0.45 \mu \mathrm{m}$ pore size nylon 66-membrane before dilution. The peak purity was assessed for each degradation solution using HPLC-PDA system and found to be passed, which demonstrates analyte peak homogeneity. A temperature controlled water bath was used to carry out the degradation studies.

Esomeprazole contains a benzimidazole ring makes the compound vulnerable to degradation. Esomeprazole shows a significant degradation in acid hydrolysis, peroxide oxidation, heat and shown a good degradation also in base hydrolysis, water hydrolysis, humidity (Fig. 4). Esomeprazole is unstable at lower $\mathrm{pH}$ and sensitive to acidic condition was degraded into Imp-B (b), Imp-C (c), Imp-E (e) and unknown impurities at RRT about $0.12,0.16,0.18,0.19,0.28,0.35,0.56,0.74$ and 1.19 by acid hydrolysis. Esomeprazole was degraded into ImpC, Imp-D, Imp-E and unknown impurities at RRT about 0.13, $0.15,0.18,0.31,0.39$ and 0.72 by oxidative hydrolysis. Esomeprazole was degraded into Imp-A, Imp-C, Imp-D, ImpE and unknown impurities at RRT about 0.12, 0.13, 0.15, 0.16, $0.18,0.21,0.25,0.31,0.39,0.41$ and 0.72 by heat. The mass balance for the degraded samples was found to be more than $95 \%$ in all the stress conditions (Table-2).

Precision: The precision of the proposed method was evaluated by injecting six individual preparations of the esomeprazole sample spiked with $1.0 \%$ of its five impurities $(1.0 \%$ of impurities with respect to $140 \mathrm{mg} / \mathrm{mL}$ esomeprazole). The $\%$ RSD of spiked impurities Imp-A, Imp-B, Imp-C, Imp-D and Imp-E was found to be less than $5 \%$, confirming the good precision of the method. The results are tabulated in Table- 3 .

Linearity: Linearity of the RS method was established by preparing a series of six concentrations (i.e., LOQ, 10, 20, 50,100 and $150 \%$ ) with $1.0 \%$ considered to be $100 \%$ by linear least square analysis method. Correlation coefficient (r), slope and y-intercept for the five impurities are presented in Table-3. The correlation coefficient obtained was greater than 0.999 , in all the impurities indicating a linear response of the impurities in the proposed method.

Limit of detection (LOD) and limit of quantification (LOQ): The LOD and the LOQ for the five impurities of esomeprazole were estimated at the concentrations for which 


\begin{tabular}{|c|c|c|c|}
\hline \multicolumn{4}{|c|}{$\begin{array}{c}\text { TABLE-2 } \\
\text { FORCED DEGRADATION DATA FOR ESOMEPRAZOLE }\end{array}$} \\
\hline Stress condition & Degradation $(\%)$ & Mass balance ${ }^{\mathrm{a}}$ & Peak purity index \\
\hline Acid $\left(0.1 \mathrm{M} \mathrm{HCl}\right.$ at $\left.25^{\circ} \mathrm{C}, 30 \mathrm{~min}\right)$ & 40.9 & 99.4 & 1.000 \\
\hline Base $\left(0.1 \mathrm{M} \mathrm{NaOH}\right.$ at $\left.60^{\circ} \mathrm{C}, 25 \mathrm{~min}\right)$ & 6.8 & 99.6 & 1.000 \\
\hline Peroxide $\left(1 \% \mathrm{H}_{2} \mathrm{O}_{2}\right.$ at $\left.60{ }^{\circ} \mathrm{C}, 20 \mathrm{~min}\right)$ & 16.0 & 99.0 & 1.000 \\
\hline Water (at $\left.60{ }^{\circ} \mathrm{C}, 20 \mathrm{~min}\right)$ & 6.4 & 99.5 & 1.000 \\
\hline Thermal (dry conditions at $105^{\circ} \mathrm{C}, 2 \mathrm{~h}$ ) & 24.5 & 99.2 & 1.000 \\
\hline Humidity $\left(25^{\circ} \mathrm{C}\right.$ and $90 \%$ RH for about 15 days) & 6.4 & 99.5 & 1.000 \\
\hline
\end{tabular}

\begin{tabular}{ccccccc}
\multicolumn{7}{c}{ TABLE-3 } \\
& REGRESSION AND PRECISION DATA FOR ESOMEPRAZOLE \\
\hline Compound & LOD (\%) & LOQ (\%) & Slope (b) & Intercept (a) & Precision (\% RSD) & LOQ Precision (\% RSD) \\
\hline ES & 0.051 & 0.061 & 15730 & 486.5 & 0.4 & 4.9 \\
Imp-A & 0.035 & 0.075 & 9673 & 38.6 & 2.6 & 4.8 \\
Imp-B & 0.031 & 0.039 & 22637 & 117.5 & 1.5 & 3.2 \\
Imp-C & 0.031 & 0.044 & 24262 & 104.3 & 0.9 & 1.8 \\
Imp-D & 0.046 & 0.064 & 17858 & 403.2 & 3.7 & 2.4 \\
Imp-E & 0.031 & 0.043 & 21660 & 404.4 & 3.8 & 2.4 \\
\hline
\end{tabular}
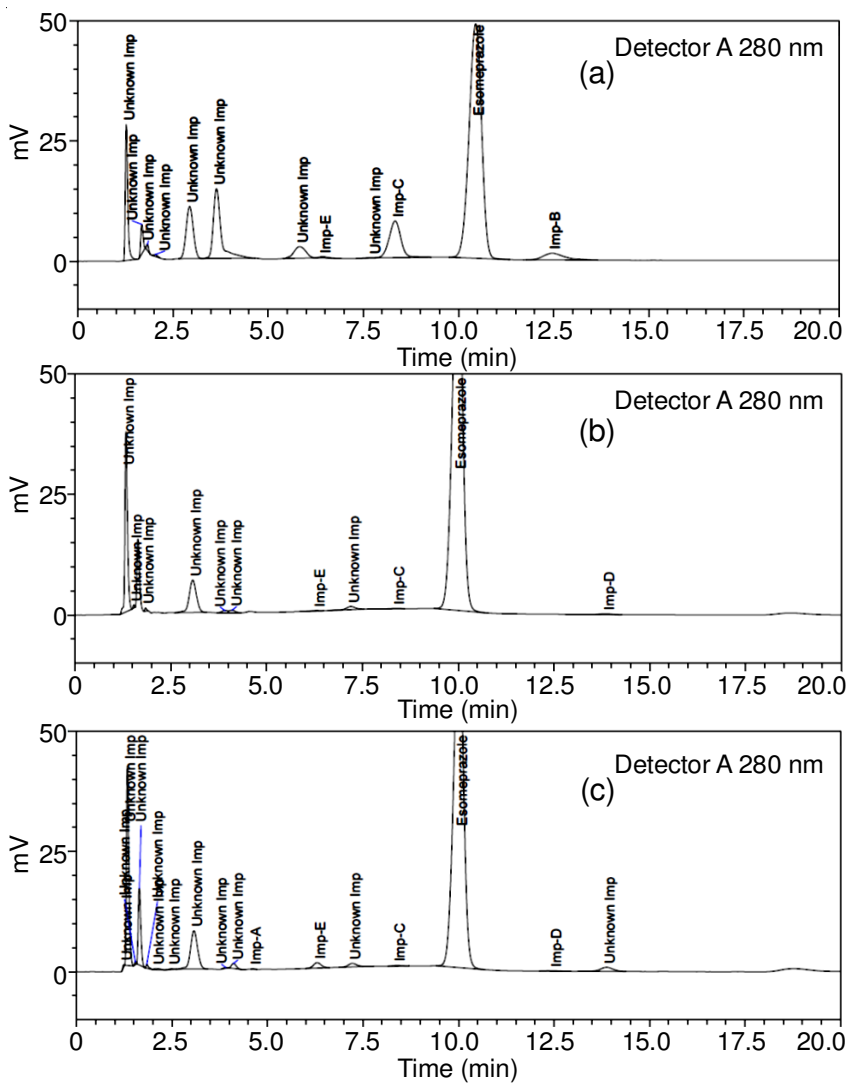

Fig. 4. Esomeprazole forced degradation chromatograms (a) acid hydrolysis (b) peroxide oxidation and (c) heat degradation signal-to-noise ratios were 3:1 and 10:1, respectively. Precision was also determined at the LOQ level by analysis of six individual preparations of the five impurities and calculating the RSD (\%). The results are tabulated in Table-3.

Accuracy: For all the five impurities percentage recovery was determined in triplicate for $0.5,1.0$ and $1.5 \%$ of the esomeprazole concentration $(140 \mathrm{mg} / \mathrm{mL})$. The results are tabulated in Table-4.

Robustness: Robustness determines the capability of the analytical method to remain unaffected by small deliberate variations in the method parameters. The conditions studied were flow rate (altered by $\pm 0.2 \mathrm{~mL} / \mathrm{min}$ ), column temperature (altered by $\pm 5{ }^{\circ} \mathrm{C}$ ) and organic phase variation (altered by \pm $10 \%$ ). Resolution between esomeprazole and Imp-D is meeting as per the EP Monograph (should be more than 3.0) in all the conditions. The results are tabulated in Table-5.

Solution stability: The stability of both standard and test solutions were verified by keeping them on benchtop for $24 \mathrm{~h}$. Both the solutions are found to be stable at benchtop and no significant change was observed for all the five impurities.

\section{Conclusion}

A green, simple, specific and reliable isocratic HPLC-DAD method was developed for the estimation of esomeprazole in their pharmaceutical formulation. The tablet dosage form was subjected to forced degradation by applying several stress conditions. Compared with the previously reported methodologies, this was the first green chromatographic method for

\begin{tabular}{cccccc}
\multicolumn{7}{c}{ TABLE-4 } \\
\hline Level (\%) & Imp-A (\% RSD) & Imp-B (\% RSD) & Imp-C (\% RSD) & Imp-D (\% RSD) & Imp-E (\% RSD) \\
\hline 50 & $100.6(2.6)$ & $99.6(1.4)$ & $101.8(2.3)$ & $100.4(1.3)$ & $101.3(3.0)$ \\
100 & $100.1(1.9)$ & $100.1(0.4)$ & $100.8(0.1)$ & $100.2(1.4)$ & $100.7(1.8)$ \\
150 & $100.3(3.3)$ & $100.5(0.3)$ & $100.2(3.5)$ & $100.1(0.7)$ & $102.1(2.5)$ \\
\hline
\end{tabular}

TABLE-5

ROBUSTNESS DATA

\begin{tabular}{cccccccc}
\hline Resolution $^{\mathrm{a}}$ & $0.8 \mathrm{~mL} / \mathrm{min}$ & $1.2 \mathrm{~mL} / \mathrm{min}$ & $45^{\circ} \mathrm{C}$ & $55^{\circ} \mathrm{C}$ & $90 \%$ IPA & $110 \%$ IPA \\
\hline Sample & 4.7 & 4.2 & 5.2 & 4.0 & 4.5 & 4.2 \\
\hline
\end{tabular}

${ }^{a}$ Resolution between esomeprazole and Imp-D was calculated. 
separation and quantification of esomeprazole and its impurities. The proposed method was successfully separated all the degradants, five known impurities and estimate the active contents. The method was validated as per ICH guidelines and found to be specific, precise, accurate, linear, rugged and robust and this chromatographic method with a run time of $20 \mathrm{~min}$ allowed the analysis of a large number of samples in a short period of time. The developed method has shown stability-indicating power, hence the developed method can be adapted to regular quality control analysis during stability studies. The replacement of acetonitrile with isopropanol provides environmentally benign alternatives to the more hazardous chemicals and processes in the field of drug/pharmaceutical analysis.

\section{ACKNOWLEDGEMENTS}

The authors thank the Management of Epione Labs Pvt. Ltd. for supporting this work.

\section{REFERENCES}

1. R.K. Gilpin and C.S. Gilkin, Anal. Chem., 79, 4275 (2007); https://doi.org/10.1021/ac070708x.

2. International Conference of Harmonisation-ICH, Impurities: Guideline for Residual Solvents Q3C (R5), Harmonised Tripartite Guideline (2011).
3. A.B. Eldin, A. Shalaby, M.S. Abdallah, M.A. Shaldam, M.A. Abdallah, Arabian J. Chem.; https://doi.org/10.1016/j.arabjc.2014.10.051.

4. S. Armenta, S. Garrigues and M. de la Guardia, Green Anal. Chem. Trends Anal. Chem., 27, 497 (2008); https://doi.org/10.1016/i.trac.2008.05.003.

5. C.J. Welch, T. Brkovic, W. Schafer and X. Gong, Green Chem., 11, 1232 (2009); https://doi.org/10.1039/b906215g

6. M. Tonini, S. Vigneri, V. Savarino and C. Scarpignato, Dig. Liver Dis., 33, 600 (2001); https://doi.org/10.1016/S1590-8658(01)80115-8.

7. P.B. Kale-Pradhan, H.K. Landry and W.T. Sypula, Ann. Pharmacother, 36, 655 (2002); https://doi.org/10.1345/aph.1A104.

8. S.U. Nalwade, V.R. Reddy, D.D. Rao and N.K. Morisetti, J. Pharm. Biomed., 57, 109 (2012); https://doi.org/10.1016/j.jpba.2011.08.025.

9. Esomeprazole Magnesium Trihydrate Monograph, European Pharmacopoeia 8.0, pp. 2168-2169 (2015).

10. A. Onal and A. Oztunc, J. Food Drug Anal., 14, 12 (2006).

11. International Conference of Harmonisation-ICH, Validation of Analytical Procedures: Text and Methodology Q2 (R1), Harmonized Tripartite Guideline (2005).

12. J.H. Clark and S.J. Tavener, Org. Process Res. Dev., 11, 149 (2007); https://doi.org/10.1021/op060160g. 